\title{
3D model related to the publication: A new species of the large-headed coastal marine turtle Solnhofia (Testudinata, Thalassochelydia) from the Late Jurassic of NW Switzerland
}

\author{
Jérémy Anquetin ${ }^{1,2 *}$, Christian Püntener ${ }^{3,4}$ \\ 1 Jurassica Museum, 2900 Porrentruy, Switzerland \\ ${ }^{2}$ Department of Geosciences, University of Fribourg, 1700 Fribourg, Switzerland \\ ${ }^{3}$ Naturmuseum Solothurn, 4500 Solothurn, Switzerland \\ ${ }^{4}$ Section d'archéologie et paléontologie, Office de la culture, République et Canton du Jura, 2900 Porrentruy, Switzerland \\ *Corresponding author: jeremy.anquetin@jurassica.ch
}

\begin{abstract}
This contribution contains the 3D surface model of the holotype cranium of the Late Jurassic thalassochelydian turtle Solnhofia brachyrhyncha described and figured in the publication of Anquetin and Püntener (2020).
\end{abstract}

Keywords: cranium, Late Jurassic, Solnhofia, Thalassochelydia

Submitted:2020-05-06, published online:2020-09-16. https://doi.org/10.18563/journal.m3.118

$\begin{array}{lll}\text { Inv nr. } & \text { Taxon } & \text { Description } \\ \text { BAN001-2.1_red } & \begin{array}{l}\text { Solnhofia } \\ \text { brachyrhyncha }\end{array} & \begin{array}{l}\text { Textured 3D sur- } \\ \text { face model of the } \\ \text { cranium }\end{array}\end{array}$

Table 1. 3D model of the holotype cranium of Solnhofia brachyrhyncha, MJSN BAN001-2.1. Collection: Jurassica Museum (formerly Musée jurassien des sciences naturelles), Porrentruy, Switzerland

\section{INTRODUCTION}

Thalassochelydian are the first turtles to diversify into marine environments. They are known mostly from the Late Jurassic of Europe (for a recent review see Anquetin et al. 2017). Among Thalassochelydia, Solnhofia parsonsi is a remarkable taxon characterized by a proportionally large head (representing about $40 \%$ of the carapace length), elongated snout, and an extensive secondary palate formed primarily by the maxillae (Gaffney 1975; Joyce 2000). In Anquetin and Püntener (2020), we described new material of Solnhofia from the Kimmeridgian of NW Switzerland. We referred this material to the new species Solnhofia brachyrhyncha, which is notably characterized by a cranium with a shorter snout and posteriorly broader triturating surface. We herein present the 3D surface model of the holotype of Solnhofia brachyrhyncha MJSN BAN001-2.1 (Fig. 1 and table 1), a relatively complete, but crushed cranium.

\section{METHODS}

The 3D surface model of the cranium MJSN BAN001-2.1 was produced by photogrammetry. The fossil was photographed in studio conditions with a $24.3 \mathrm{Mpx}$ Nikon ${ }^{\circledR}$ D610 camera equipped with a $60.0 \mathrm{~mm}$ macro lens. A set of 174 photographs from different orientations and angles was developed in Photoshop Camera Raw 6.7 (Adobe) and contrasts were enhanced. Masks were created for each photograph with Photoshop CS5 (Adobe). Photographs and corresponding masks were processed with the photogrammetry software Photoscan 1.0.4 Standard Edition (Agisoft), following the procedures described by Mallison and Wings (2014). The 3D surface model is provided in .ply format with an associated texture file in .png format, and can therefore be opened with a wide range of freeware.

\section{ACKNOWLEDGEMENTS}

We are thankful to the photographers Bernard Migy (photography) and Olivier Noaillon (post-processing) of the former Section d'archéologie et paléontologie (Paléontologie A16) for producing the set of photographs that we used for photogrammetry. This work was funded by a grant from the Swiss National Science Foundation (SNF 205321_175978) to JA. The Paleontology A16 project was funded by the Federal Roads Office (FEDRO, 95\%) and the Republic and Canton of Jura (RCJU, 5\%).

\section{BIBLIOGRAPHY}

Anquetin, J., Püntener, C., 2020. A new species of the largeheaded coastal marine turtle Solnhofia (Testudinata, Thalassochelydia) from the Late Jurassic of NW Switzerland. PeerJ. In press.

Anquetin, J., Püntener, C., Joyce, W. G., 2017. A review of the fossil record of turtles of the clade Thalassochelydia. Bulletin of the Peabody Museum of Natural History 58, 317-369. https: //doi.org/10.3374/014.058.0205

Gaffney, E. S., 1975. Solnhofia parsonsi, a new cryptodiran turtle from the Late Jurassic of Europe. American Museum Novitates 2576, 1-22.

Joyce, W. G., 2000. The first complete skeleton of Solnhofia parsonsi (Cryptodira, Eurysternidae) from the Upper Jurassic of 
A
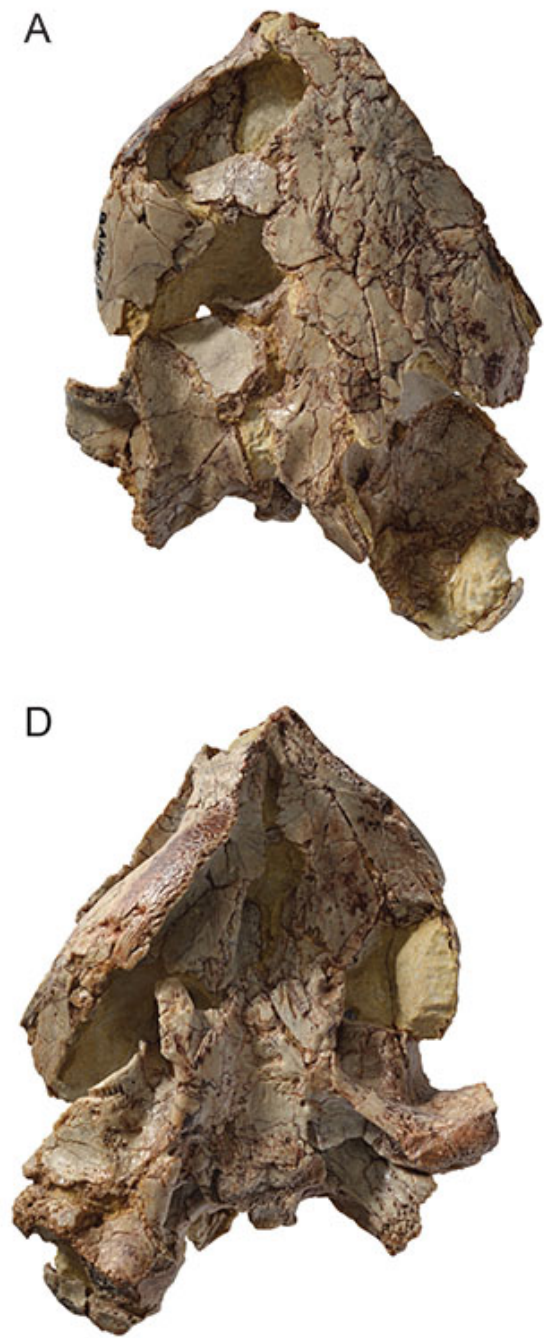

B

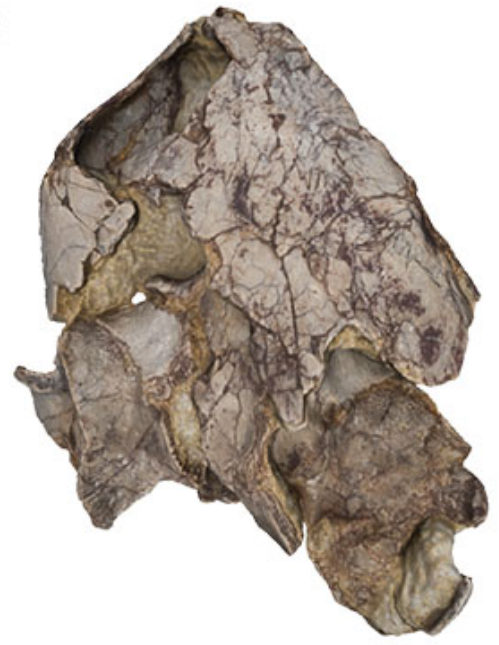

$\mathrm{E}$

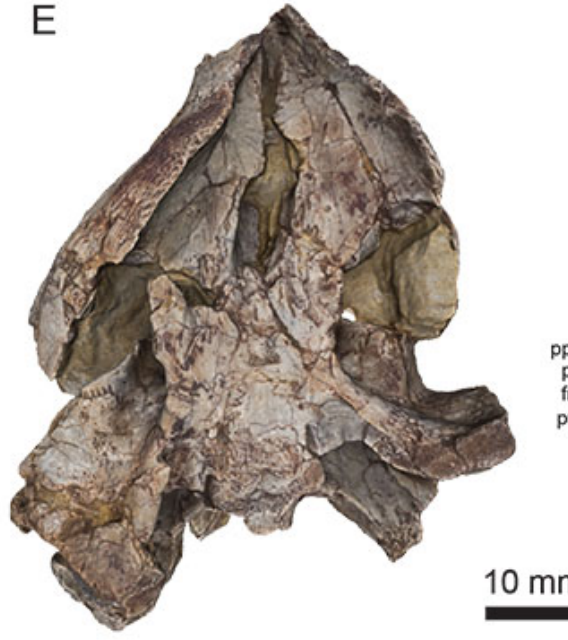

C

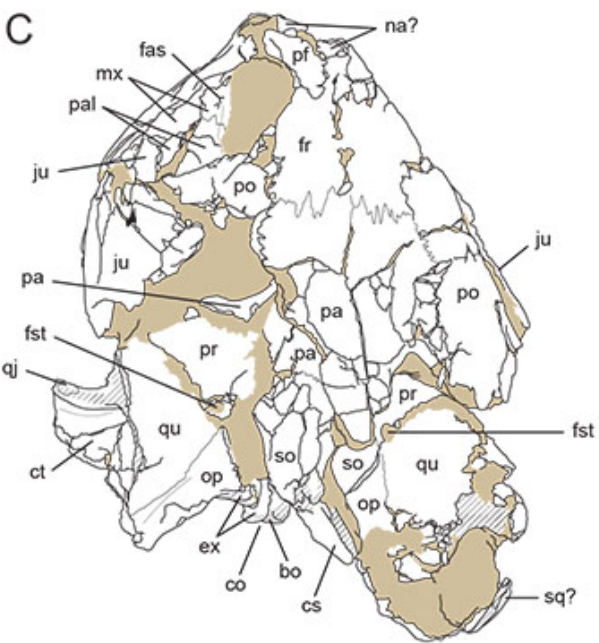

$\mathrm{F}$

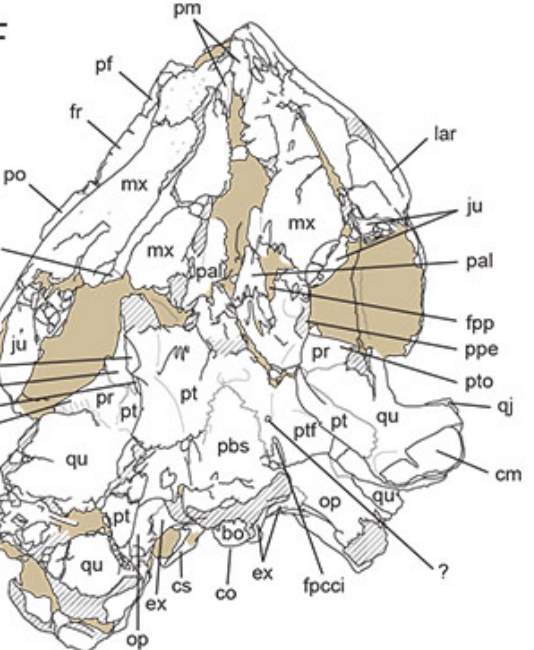

Figure 1. MJSN BAN001-2.1, holotype of Solnhofia brachyrhyncha (Kimmeridgian, Porrentruy, Switzerland). Photograph (A), 3D model (B) and interpretative drawing $(\mathbf{C})$ of the cranium in dorsal view; Photograph (D), 3D model (E) and interpretative drawing (F) of the cranium in ventral view. In the drawings, hatchings correspond to damaged areas, while the light brown color represents the remaining matrix. Abbreviations: bo, basioccipital; cm, condylus mandibularis; co, condylus occipitalis; cs, crista supraoccipitalis; ct, cavum tympani; ex, exoccipital; fas, foramen alveolare superius; fnt, foramen nervi trigemini; fpcci, foramen posterius canalis carotici interni; fpp, foramen palatinum posterius; fr, fontal; fst, foramen stapedio-temporale; ju, jugal; lar, labial ridge; mx, maxilla; na, nasal; op, opisthotic; pa, parietal; pal, palatine; pbs, parabasisphenoid; pf, prefrontal; pm, premaxilla; po, postorbital; ppe, processus pterygoideus externus; pr, prootic; pt, pterygoid; ptf, pterygoid fossa; pto, processus trochlearis oticum; qj, quadratojugal; qu, quadrate; so, supraoccipital; sq, squamosal; ?, unnamed foramen. 
Germany and its taxonomic implications. Journal of Paleonto$\operatorname{logy}$ 74, 684-700. https://doi.org/10.1017/S00223360000328 07

Mallison, H., Wings, O., 2014. Photogrammetry in paleontology - A practical guide. Journal of Paleontological Techniques 12, $1-30$. 